\title{
The Death Of High Performance Programs: Transferring Knowledge In The New Millennial
}

Dr. Mary E. Donohue, CEO of Donohue Learning TM and Dalhousie University, Canada.

\begin{abstract}
The "Opportunity Gap" and the "Skills Gap" have been the focus of conferences this year. Solutions have been proposed, but none has aligned technology with the cultural capital that exists within an organization to close the gaps. Cultural capital is the accumulation of symbols, language, political knowledge and expertise that senior leaders use to get the job done daily within an organization. Emerging leaders who have not been immersed in this cultural capital, particularly diverse candidates, struggle to identify or find the resources and develop the skills necessary to succeed in an organization. Frequently training dollars are allocated to high-potential candidates who often are able to assimilate these skills quickly, but rarely if ever are they, when at the managerial level, tested on their ability to transfer these skills to others. This inability of high-potential mangers to transfer cultural capital between the different layers of an organization is a real cause of the skills and opportunity gap.
\end{abstract}

In 2012, at a larger retailer in the southern US, we began testing a pilot program for a practical management training in the form of a Licensed Online Open Course (modeled after the MOOC) to determine if managers with access to a structured and disciplined curriculum could have an impact on human capital productivity and increase retention among managers and their followers. The LOOC and its content were created by the Donohue Mentoring System $^{\mathrm{TM}}(D M S)$.

We concluded that on-the-job training, using the DMS LOOC delivery and mentoring, fosters cultural capital, increased job motivation and satisfaction, and subsequently increased output (productivity) by 10\%. Using a survey comprised of 19 questions, we were also able to determine that trust in superior officers increased by $10 \%$ and selfassessed value of work increased by $10 \%$. These increases resulted in a reduced employee chum of 50\%. As we carried on pilots in 2013, 2014 and 2015 with other large corporations, not for profit and a government, we were surprised to find that the system delivered the same noteworthy results each time. We found that when managers are presented with a technology solution that allows them to train candidates (mentees) and transfer knowledge to their mentees, leadership magic happens, and people engage with each other. What surprised us the most was that no matter the size of the pilot program, mentees for the most part surpassed their mentors' knowledge pre-program.

Keywords: Leadership Training; Millennials; Culture; Whole Person Learning; Leadership; Diversity; Training; Technology; Communication; Internal Communications

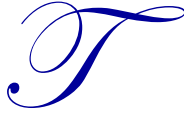

his report is based on quantitative and qualitative data from 300 participants from 2012 - 2014. Its purpose was to understand the impact of technology and mentoring on mid-level leaders and their followers including and often specific to self-identified diverse candidates within an organization.

It also examined how the Donohue Mentoring System ${ }^{\mathrm{TM}}$, delivered via a Licensed Online Open Course, impacted work satisfaction, retention and productivity of this group. 


\section{THE DEATH OF HIGH-PERFORMANCE PROGRAMS}

Limiting yourself to leadership development for high performers is akin to the captain of the Titanic only worrying about the tip of the iceberg. What/who matters is below and out of sight of most training and development professionals. This lack of inclusionary training is one of the drivers of the opportunity and skills gap emerging in today's economy.

Today's workforce train ing is designed in much the same way workforce train ing was orientated post WWII; i.e., focus on the top and that knowledge will flow down to the bottom. However, in the last 25 years, because of outsourcing of training, high-potential programs are no longer transferring internal cultural knowledge from one employee to another. If such a program transfers knowledge to a team at all, it is an idea or program that worked for another company, not what may necessarily work for the new business. Technology poses another problem for knowledge transfer; often people will write an email or text to sum up what they have learned, but that information doesn't resonate with the team member who did not attend the training. "Trickle down" training is not effective; mistrust develops and the programs never really take off.

In 1943 Kurt Lewin stated that behavior is a function of people and the environment. Yet today's tech based, taskfocused workplaces have forgotten to how to connect people and their environment (culture). Attendees at the Milken Institute Global Conference in May 2015 discussed the concept that is now defined as the "Opportunity Gap" -- how can people get ahead. Bloomberg, aga in in May, discussed the "Skills Gap," defined as the difference between the skills new hires have and employers really want. In 2015, Silicon Valley became obsessed with diversity and the apparent lack of diversity within their high-tech organizations .

All of these labels are the busy-ness of business. They are things that "management" like to dig into and review, but rarely if anything comes of it. Everyone loves to talk, but only the courageous take a chance and act. The companies we worked with realized this and took a chance and acted. They began to in-source training for mid-level leaders by using high-potential leaders with cultural capital.

High-potential programs and leadership programs are where most of the corporate training dollars are spent. The open question is how effective the training has been. Beginning in 2007, I began to research the effects of refocusing the labor force, using knowledge that was already embedded in a company within mid-level to senior leaders through mentoring. No outside consultants necessary, no expensive training, just knowledge transfer that is measured, structured and scalable, enabling the process to be duplicated where it is needed. All in an effort to increase work satisfaction, retention and productivity.

\section{DMS IN-SOURCING AS A SOLUTION}

\section{In-Sourcing}

Dearden, Reed and Van Reenen (2006), demonstrated that "work-related training is associated with significantly higher productivity." De Grip \& Sauermann (2012) found that "participation in training programs leads to a $10 \%$ increase in performance." Springer, (2011) states "by applying managerial strategies to increase job motivation and job satisfaction, managers can improve bank employees' job performance." Our findings agree with these findings, and in fact demonstrate that when given a practical solution for training delivery managers can assist all team members and especially diverse candidates to increase performance by $15 \%$ and close the opportunity gap in as little as 18 months.

In-sourcing through the Donohue Mentoring System(DMS) connects high potentials with emerg ing leaders to build cultural capital and move the business forward. Our success demonstrates that when you provide star employees with the tools that enable them teach and mentor others in the company, a positive culture change results $80 \%$ of the time. Teams are impacted in 12-16 weeks and are more engaged, productive and happier. The effects of this teaching, our research has demonstrated, are lasting for periods exceeding 12 months. In-sourcing, using the DMS 
technology, connects high potentials with emerging leaders in the organization, and or diverse candidates. It provides them a technology-based customized road map that builds community capital by building value, engagement and trust among teams.

The DMS technology provides companies with the tools to close both the skills and opportunity gap by refocusing the labor force, enabling teams to complete their tasks in an efficient and productive manner.

\section{DEFINING THE GAPS}

The opportunity gap focuses on the unequal opportunity that people face in today's workforce.

The Bloomberg Skills Gap is an impactful visual that shows skills that are needed and recommends that people take very expensive MBA programs to develop these skills. This is an old schoolsolution for new economy problems.

Attracting and retaining diverse talent is not a numbers game. Our research demonstrates that well-executed inclusive activities that are built on knowledge transfer and mentorship produce a more dynamic and creative workforce and reduces the cost of new hires.

\section{CLOSING THE GAP}

Isolation is defined as an employee's inability to find resources to solve problems that arise every day in the workforce that have not been predicted nor discussed during the on-boarding process. Examples that our research has uncovered include the disturbing feeling of an emerging leader not seeing people who look like them in senior leadership roles and therefore not immediately identifying the cultural norms of their organization; not appreciating how to approach senior leadership for help without looking weak; and not being able to deal with changing leadership and the cultural shifts that often follow with this change. Isolation, particularly for young women, is also caused by gender "carding"; meaning, men asking wo men to identify their priorities during each job review they take part in. It was amazing how many women told us that they were asked about their priorities as parents and workers. The book Lean In by Sheryl Sandberg offers revealing examples of gender carding, as well as the guilt game women create for themselves about motherhood.

This isolation is not just limited to workers; senior managers and leadership feel this isolation as well. Examples ou r participants shared included the feeling that they don't have time to develop people, because if they do they risk not completing tasks that are related to achieving their bonus; although they are told to build a team, they are not given a roadmap for team building; and although they are told to develop new leadership they are not rewarded for developing people, but rather they are rewarded for bottom-line performance, so they don't spend time on developing young talent.

Almost every company says something on its website or in their year-end report to the effect of we put our people first. But how many of them talk about the programs and the measurements that demonstrate they put people first? How many year-end reports show the financial rewards of developing people?

You can't close a gap if people aren't engaged with the company and its culture.

\section{ISOLATION IS NOT HOW WE NEED TO WORK IN THE 21 ${ }^{\text {ST }}$ CENTURY}

Today's workforce is made up of not only different genders, but different ethnicities and different family experiences, which demands that problem solving be more creative. These differences also create roadblocks for people who don't know the right way to solve a problem within a culture. For example, one of our participants in a DMS program noted that his schooling taught him to not respond quickly to an email, because if you delay a response you demonstrate that thought and care went into the reply. His new culture expected immediate responses, yet he was never informed of this trait of his company's culture. He believed he was demonstrating thoughtful 
behavior and his boss thought he was slow on the uptake. Another employee was taught to never talk about family or have family photos on a desk, that was unprofessional. His new work encouraged family "water cooler" chats. This dichotomy of cultural norms caused his work colleagues to think he was cold and unapproachable, furthering a stereotype of his culture.

No one person in management could identify these issues because they were focused on task, not on development. Therefore, in their reviews these stellar hires were seen as floundering in the work culture.

Task-based management does not work when you need workers who can think. Thinking is defined as interacting with consumers or clients and provide solutions on a daily basis. To think, you need to learn; and to learn, you need teachers. We are not developing workplace teachers who can solve problems; therefore, we are not developing a workforce, but only workers who feel they have no power, who feel they are isolated from the "boss."

If you read exit interviews, you find the people are leaving people -- they are not leaving tasks, yet we still find that tasks are what are rewarding in the traditional review process, so tasks are what leaders focus on and build their days around.

\section{COUNTERACTING THE NEGATIVE EFFECTS OF ISOLATION}

Ask yourself how you and your leaders are equipping their followers to deal with our ever-changing reality that is today's workplace. How are you reducing the negative effects of isolation which include lack of trust, churn, and an inability for teams to innovate and sell at their highest potential?

You have to create teams of great workers instead of only high-potentials programs. I call it the Isolation Theory. Think about an iceberg; you only see the top 10 percent of the mass, but that is not what is moving the iceberg forward. It's the ocean currents driving the submerged mass that can wreak havoc on vessels.

Star people don't build a great company; star teams do. Just ask Pixar, Google, Facebook and Apple.

To create star teams, you have to transfer your problem-solving capital from one employee to another in a systematic manner that results in a strong sense of belonging and commitment to the company to build profit. Our research demonstrates that people are no longer motivated by star leaders -- they are motivated by a desire to be on star teams.

History has proven that people are willing to work to build a corporate profit if they know how this profit will benefit them or the community. We have found this desire to be ignited by a very simple connection; I want to help Paul achieve a goal because if he does "X," what will happen to me or what we are building together will benefit the world, and I need to be a part of this as it aligns with my moral purpose.

Star teams develop team members through peer-based systematic problem solving, otherwise known as mentoring. Our early intervention learning and development technology introduces both mentors and mentees to nine foundational conversations to build both their skills and team members skills. Each foundational conversation builds upon the prior conversation. It takes an hour a week, mentors and mentees are connected to the whole using a learning environment, and the program is taught in a cohort. One of the key factors in learning is the impact of community - the people whom we learn with and from. Based on the importance of community at work, Cohort learning at the workplace creates a community of mentors and mentees that learn to depend on each other and discuss the curriculum (conversations) with each other.

\section{ISOLATION AND THE NEED TO CONNECT}

As reported by Cuddy, Kohut and Neffinger in Harvard Business Review July- August 2012, psychologists argue that the drive to connect with others at work ranks among our primary need as humans. When you teach others to 
ask team me mbers rather than rely on outside resources to solve problems, you meet this need, and the result is that individuals build teams that are more creative and efficient in generating internal solutions.

Our model is based on this need to connect. We use a series of conversations that build one upon another to transfer problem-solving capital from senior leaders to junior leaders in weekly, or monthly lessons, with one conversation building on the next. Each conversation is framed and delivered across Learning Environment. This a llows each team to receive the same information on the same time minimizing fluctuations in training and messaging. And the model closes the opportunity and skills gap.

It does so because our mentoring system requires leaders to articulate, through nine foundational conversations, how to get the job done; it draws their problem solving capital out and transfers this knowledge to their mentees. Think of it as a knowledge transfer circuit training program. We present teams with specific goals for each conversation that involve using the perspective of the senior leader and the mission of the organization. They rise to the challenge and in the process develop relationships that last. We also collect data every step of the way enabling our team to report on who is engaged and who is not engaged in the process. This allows corporations to identify team members who are having difficulties.

The model builds from the basic to the complex: 1) how do we learn, 2) how do we listen, 3) what is our default communication style, 4) how to we give feedback 5) how do we accept feedback, 6) how do we frame a difficult conversation, 7) what is your ethical code, 8) what is your moral code, and 9) how do your morals and ethics tie into how we do business. They unlock the value of people's work ethic by investing in mentoring that is disciplined, measured and saleable.

\section{CONCLUSION}

What is fascinating about DMS mentoring is that since 2012, mentees have almost risen to or exceeded the pre-test results of mentors in both adaptability and resilience, demonstrating that the mentors in our program were extremely successful in transferring their problem-solving skills to their mentees. We create super teams that are adaptable and resilient.

The benefit of this system is that you create more opportunity and increase skills because you create a more motivated workforce. This leads to lower churn and higher productivity. In fact, in a review of individual results, using our trademark measurement, $80 \%$ of participants rated themselves as better equipped to deal with change and as more highly motivated to come to work every day. They like their jobs and their teams better.

If people like their jobs, their teams and their bosses, they will develop skills and they will find opportunity through teamwork.

When thinking about where to invest your dollars, think about the Titanic; it wasn't the tip of the iceberg that sunk the ship -- it was what was under the water.

\section{FURTHER RESEARCH}

The purpose of this report was to understand the impact of technology and mentoring on 300 mid-level leaders and their followers in an organization. Although this study found that positive results were realized for mentoring based on technology-driven outcomes, further research using larger groups pulled from a global audience is recommended. 


\section{AUTHOR BIOGRAPHY}

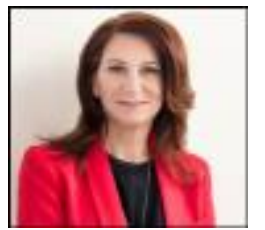

Named as one of the 18 Outstanding Women In Tech, 2015, and Diversity MBA's top 50 under 50 in 2015, Dr. Donohue is a passionate advocate of revolutionizing today's workforce training through technology and developing internal talent. Her book with Jack Canfield became a best seller on A mazon in the both the US and Canada in September 2015. Mary is a cancer survivor who worked with Paul Newman, learned from Robert Kennedy, Jr., made her movie debut with former Toronto Mayor David Miller, and was briefly (very briefly) a Supreme with Diana Ross.

As Founder of Donohue Learning TM, she designs systems that provide people with a roadmap to become people developers and achieve a better work/life balance. Her clients include Walmart, American Airlines, Kaiser Permanente, OLG, and many other private and public organizations.

Dr. Mary is a world-renowned speaker and TEDX presenter, television personality and columnist. Her work appears in the Huffington Post and Financial Post. She has won awards for her volunteerism and research and continues to give back daily to her community both domestically and internationally.

Dr. Donohue is currently an Adjunct Professor, Graduate School of Management, Dalhousie University, in Halifax, Nova Scotia and can be reached at mary@thedms.org, 4165642944.

\section{REFERENCES}

Dearden, L., Reed, H. and Van Reenen, J. (2006), The Impact of Training on Productivity and Wages: Evidence from British Panel Data. Oxford Bulletin of Economics and Statistics, 68: 397-421. doi: 10.1111/j.1468-0084.2006.00170.x

De Grip, A. and Sauermann, J. (2012), The Effects of Training on Own and Co-worker Productivity: Evidence from a Field Experiment. The Economic Journal, 122: 376-399. doi: 10.1111/j.1468-0297.2012.02500.xDonohue, M. (2009). The effect of mentoring on mid-level leaders. Mt. Pleasant, MI: Central Michigan University.

Donohue, M, Carter, E. \& Jensen, M. (2010). Whole person and mentoring. Proceedings of the MEA 2010 conference (pp. 64). Seattle, WA: MEA Conference.Frye, Northrop (1963). The educatedimagination. Bloomington, IN: Indiana University Press.

Hatch, J. A. (2002). Doing qualitative research in education settings. Albany, NY: State University of New York Press.

Howe, N, \& Strauss, W. (2000). Millennials rising: The next great generation. New York, NY: Random House Inc.

New Strategist Editors, Initials. (Ed.). (2004). The millennials: Americans born 1977 to 1994. Ithaca, NY: New Strategist Publications Inc.

Sandberg, S. (2013). Lean in: Women, work, and the will to lead (First edition.). New York: Alfred A. Knopf. Shaw, H. (2007, June 15).

Smith, C. (1999). The effects of corporate culture on mentoring relationships. (Unpublished doctoral dissertation . New York University School of Social Work, New Work.

Statistics Canada . (2006). Demographics.. Ottawa: Government of Canada.

Springer, Gary Jon. 2011. A Study Of Job Motivation, Satisfaction, And Performance Among Bank Employ ees. Journal of Global Business Issues. 5(1), pp:29-42.

The Bloomberg Recruiter Report: Job Skills Companies Want But Can't Get. (2-15, February). Retrieved June 6, 23, from http://www.bloomberg.com/graphics/2015-job-skills-report/

Levy, F., \& Cannon, C. (2016, February 9). The Bloomberg Job Skills Report 2016: What Recruiters Want. Retrieved April 04, 2016, from http://www.bloomberg.com/graphics/2016-job-skills-report/.

Winograd, M.\& Hais, M.(2008). Millennial makeover: MySpace, YouTube, and the future of American politics. New Brunswick, NJ: Rutgers Press.

Zax, D. (2010, October 14). For millennials, brands may be as important as religion, ethnicity. Retrieved from http://www.fastcomp any.com/1695062/brands-and-millenials-a-deep-connection. 